\title{
Development of eco earth-moist concrete
}

\author{
G. Hüsken \& H.J.H. Brouwers \\ University of Twente, Faculty of Engineering Technology, Department of Civil Engineering, The Netherlands
}

\begin{abstract}
This paper addresses experiments on eco earth-moist concrete (EMC) based on the ideas of a new mix design concept. Derived from packing theories, a new and performance based concept for the mix design of EMC is introduced and discussed in detail. Within the new mix design concept, the grading line of Andreasen \& Andersen (1930), modified by Funk \& Dinger (1994), is used for the mix proportioning of concrete mixtures. The innovative part of this approach is to consider the grading of the entire mix as an optimization problem. The formulation and solution of the optimization problem will be explained and validated by experiments on EMC. Therefore, mixes consisting of a blend of slag cement and Portland cement, gravel (4-16), granite (2-8), three types of sand (0-1, 0-2 and $0-4)$ and a polycarboxylic ether type superplasticizer are designed using the new mix design concept and tested on lab sale.
\end{abstract}

\section{INTRODUCTION}

The mass production of concrete products like concrete pipes, slabs, paving blocks and curb stones is based on the advantageous working properties of earth-moist concrete (EMC). So, in comparison to normal-weight concrete, the dry consistency of EMC allows for direct stripping of concrete products after filling and vibrating the molds. As a result, short processing times of the production process can be realized.

Traditional EMC mixes are characterized by high cement contents between $350 \mathrm{~kg}$ and $400 \mathrm{~kg}$ per $\mathrm{m}^{3}$ concrete and low content of fine inert particles. Besides, they show low water/cement ratios $(w / c<$ $0.4)$ combined with stiff consistency and high degree of compactibility. As a result of low water/cement ratios, high compressive strength values are achieved by EMC mixes and the durability is improved compared to ordinary concrete.

However, despite these positive properties there is potential for improvements regarding the workability, green strength, packing density and reduction of cement content by using secondary waste materials. An optimization of the particle packing and the ratio of water in voids, in consideration of the material properties of the available raw materials, can lead to an increase in the green strength of the fresh concrete and also to higher compressive strength values of the concrete in hardened state.

This enormous potential for optimizing EMC mixes is the starting point for the development of a new and performance based mix design concept.

\section{PARTICLE PACKING IN CONCRETE}

The packing of the solids is of essential importance for the properties of fresh and hardened concrete. By the help of the fundamental understanding of the working mechanism of particle packing it is possible to control the behavior and the characteristics of products based on granular materials. Therefore, a lot of research into the field of particle packing was carried out in the last century. Based on the work of Fuller \& Thomsen (1907), Andreasen \& Andersen (1930) studied the packing of continuously graded particles and led them to the semi-empirical equation for the cumulative volume fraction $F(D)$ :

$F(D)=\left(\frac{D}{D_{\max }}\right)^{q} \quad \forall D \in\left[0, D_{\text {max }}\right]$

where $D=$ particle size; $D_{\max }=$ maximum particle size; and $q=$ distribution modulus.

Numerous publications afterwards refer to Equation 1 using a distribution modulus of $1 / 2$ as 'Fuller curve' or 'Fuller parabola'. Also Hummel (1959) referred to the Fuller curve for composing aggregates used in standard concrete. The Fuller curve is also used by most of the European standards for composing concrete and is located within the recommended area between sieve line A and B of the Dutch standard NEN 5950 (1995) (cp. Figure 1).

Analyzing the mix design concepts it becomes obvious that the Fuller curve is applied for the grading of aggregates bigger than $250 \mu \mathrm{m}$ only. This limitation has as a consequence that maximum amounts of fine 


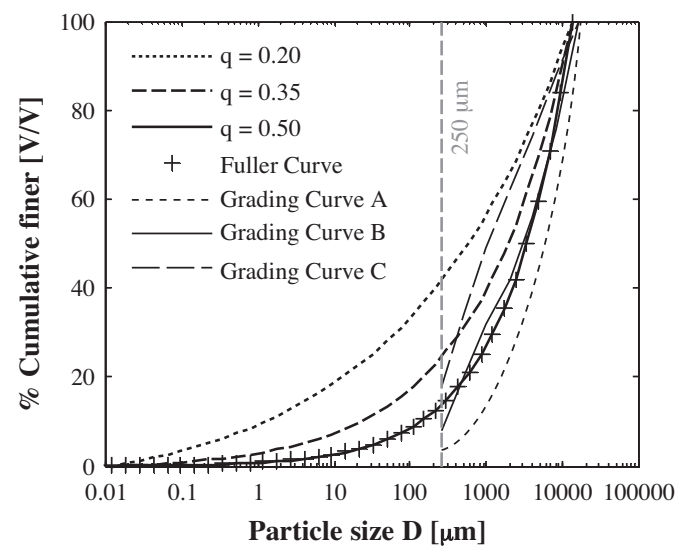

Figure 1. Equation 2 for varying distribution moduli using $D_{\max }=16 \mathrm{~mm}, D_{\min }=0.01 \mu \mathrm{m}$ and grading curves A, B and C according to NEN 5950 (1995) as well as Fuller curve.

material are prescribed but without considering the granulometric properties of the fine material. This will not be the case under practical conditions as there will always be a minimum particle size depending on the grading of the ingredients used. Accordingly, a modified version of Equation 1 was introduced by Funk \& Dinger (1994) which prescribes the grading for continuously graded aggregates considering a minimum and maximum particle size in the mix. This modified equation for the cumulative volume fraction $F(D)$ reads:

$F(D)=\frac{D^{q}-D_{\min }^{q}}{D_{\max }^{q}-D_{\min }^{q}} \quad \forall D \in\left[D_{\min }, D_{\max }\right]$

where $D=$ particle size; $D_{\min }=$ minimum particle size; $D_{\max }=$ maximum particle size; and $q=$ distribution modulus. According to Figure 1, it can be assumed that the Fuller curve and Equation 2 using $q=0.5$ seem to be concordant if both graphs are compared only visual. But this is not the case as the difference of the functional values becomes more relevant the closer $D$ approaches $D_{\min }$.

In Equation 2, the distribution modulus $q$ influences the ratio between coarse and fine particles and allows therefore the composition of ideal graded mixtures for different types of concrete having special requirements on the workability by using one equation for the aimed grading line. Higher values of the distribution modulus $(q>0.5)$ are leading to coarse mixtures whereas smaller values $(q<0.25)$ are resulting in mixtures which are rich in fine particles. Own experiments showed that appropriate values for $q$ are in the range between 0.35 and 0.40 for EMC.

\section{MIX DESIGN CONCEPT}

In concrete technology, ingredients with a wide spread range of particle size distributions (PSDs) are combined and therefore different approaches can be found for the composition of concrete mixtures. The idea of the new mix design concept is to design a performance based concrete mix considering the granulometric properties of all solid raw materials. This idea is realized by the formulation of an optimization problem using the modified equation of Andreasen and Andersen (Equation 2).

The positive influence of the modified A\&A equation on the properties of self-compacting concrete (SCC) was already shown by Brouwers \& Radix (2005), and Hunger \& Brouwers (2006). Furthermore, the suitability of the modified A\&A equation was shown by Schmidt et al. (2005) for EMC. However, an aimed optimization of the grading line of the composed concrete mixes in consideration of Equation 2 was not carried out by Schmidt et al. (2005). The application of the modified A\&A equation is constricted in this case to a comparison in the shape of the curve of the various composed mixes and Equation 2 using different distribution moduli.

Hence, it appears that an aimed composition of the concrete mix considering the grading line given by Equation 2 can result in concrete that meets the required performance properties. Therefore, an algorithm was developed which helps to compose the concrete mix according to the PSD given by the modified A\&A equation based on $m$ ingredients $(k=$ $1,2, \ldots, m)$, including the non-solid ingredients air and water.

For proportioning the aggregates using Equation 2, as particle size $D$ in Equation 2 is taken the geometric mean of the upper and lower sieve size of the respective fraction obtained by sieve analysis or laser diffraction analysis as follows:

$D_{i}^{i+1}=\sqrt{D_{i} D_{i+1}} \quad$ for $i=1,2, \ldots, n-1$

The sizes of the fractions vary in steps of $\sqrt{ } 2$ starting from $0.01 \mu \mathrm{m}$ up to $125 \mathrm{~mm}$. Consequently, 44 sizes $(i=1,2, \ldots, n+1)$ are present and 43 fractions (n) are available for the classification of the $m-2$ solid ingredients.

Taking this wide range in the PSDs of the granular ingredients into account, the entire grading of all aggregates, binders, and filler materials will be considered in the mix design to obtain an optimized packing. As mentioned in the beginning, the mix design concept will result in the formulation of an optimization problem and requires therefore the definition of the optimization problem via:
- Target value
- Adjustable values
- Constraints 


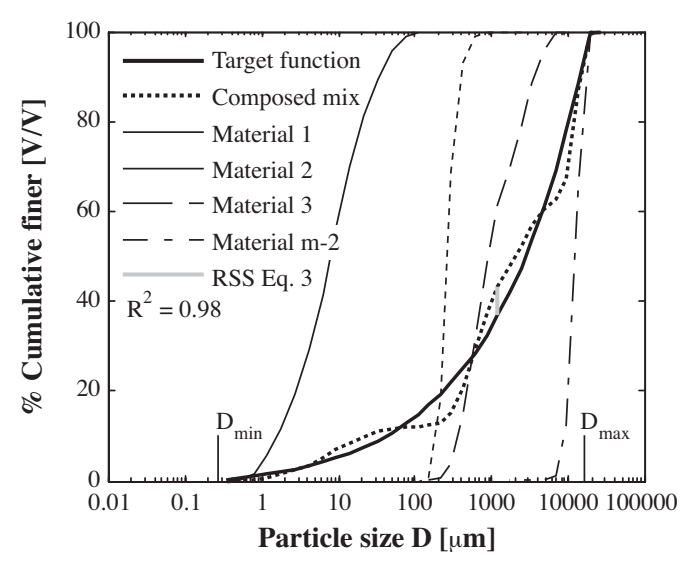

Figure 2. Composed aggregate mix; $D_{\max }=16 \mathrm{~mm}$, $D_{\min }=0.275, q=0.35$.

\subsection{Target value}

The target value represents the objective of the optimization problem. This value shall either be minimized or maximized. In the considered case, the deviation between the desired grading of the composed mixture $F_{m i x}(D)$ (Equation 8 ) and the grading given by the target function $F_{\mathrm{tar}}(D)$ (Equation 2) shall reach a minimum and results, in other words, in a curve fitting problem. To solve this curve fitting problem, the least squares technique is commonly used. Thereby, the sum of the squares of the residuals RSS is minimized. Equation 4 expresses the least squares technique mathematically.

$$
\begin{aligned}
R S S:=\sum_{i=1}^{n} e_{i}^{2} & =\sum_{i=1}^{n}\left(F_{\text {mix }}\left(D_{i}^{i+1}\right)-F_{\text {tar }}\left(D_{i}^{i+1}\right)\right)^{2} \rightarrow \min !(4) \\
\text { with } F_{\text {tar }}\left(D_{i}^{i+1}\right) & =\frac{\left(D_{i}^{i+1}\right)^{q}-D_{\min }^{q}}{D_{\text {max }}^{q}-D_{\min }^{q}} \quad \forall D_{i}^{i+1} \in\left[D_{\text {min }}, D_{\max }\right] \\
D_{\min } & =D_{i} \quad \text { for } F\left(D_{i-1}\right)=0 \wedge F\left(D_{i}\right)>0 \\
D_{\max } & =D_{i} \quad \text { for } F\left(D_{i-1}\right)<100 \wedge F\left(D_{i}\right)=100
\end{aligned}
$$

As criterion for evaluating the quality of the curve fit, the coefficient of determination $\mathrm{R}^{2}$ is used. Figure 2 shows as an example the grading of a composed aggregate mix based on 4 solid ingredients $(\mathrm{m}-2)$.

This figure illustrates that by combining four ingredients only, that each have their own PSD, a mix can be designed that closely follows the specified target PSD given by Equation 2.

\subsection{Variables}

The variables are adjustable values on the system. Changeable values are used by the optimization algorithm to approach the target value. Values which can be changed in the system are the total volume of solids
$V_{\text {sol }}^{\text {tot }}$ and the volumetric proportion $v_{\text {sol }, k}$ of each solid ingredient.

$$
\begin{aligned}
& V_{\text {sol }}^{\text {tot }}=\sum_{k=1}^{m-2} V_{\text {sol }, k} \\
& v_{\text {sol }, k}=\frac{V_{\text {sol }, k}}{V_{\text {sol }}^{\text {tot }}}
\end{aligned} \quad \text { for } k=1,2, \ldots, m-2
$$

The volumetric proportion $v_{\text {sol, } k}$ of each solid component influences the grading (computed sieve residue $\left.P_{m i x}\left(D_{i}\right)\right)$ of the composed mix via:

$$
P_{m i x}\left(D_{i}\right)=\frac{\sum_{k=1}^{m-2} \frac{v_{s o l, k}}{\rho_{s o l, k}^{s p e}} P_{\text {sol }, k}\left(D_{i}\right)}{\sum_{i=1}^{n} \sum_{k=1}^{m-2} \frac{v_{s o l, k}}{\rho_{s o l, k}^{s p e}} P_{\text {sol }, k}\left(D_{i}\right)}
$$

where $P_{\text {sol,k }}\left(D_{i}\right)=$ sieve residue of solid $k$ on the sieve with the mesh size $D_{i}$; and $\rho_{\text {sol }, k}^{\text {spe }}=$ specific density of solid $k$. And finally, the computed cumulative finer fraction of the composed mix is given by:

$F_{\text {mix }}\left(D_{i}^{i+1}\right)= \begin{cases}F_{\text {mix }}\left(D_{i-1}^{i}\right)-P_{\text {mix }}\left(D_{i}\right) & \text { for } i=1,2, \ldots, n-1 \\ 1 & \text { for } i=n\end{cases}$

As mentioned before, the total volume of solids $V_{s o l}^{t o t}$ per $\mathrm{m}^{3}$ fresh concrete is also changed by the optimization algorithm. This value is not directly connected with the target value. Here, a connection exists via the constraints.

\subsection{Constraints}

Constraints are used to express real-world limits (physical constraints) or boundary conditions (policy and/or logical constraints) of the formulated optimization problem. Physical constraints are determined by the physical nature of the optimization problem whereas policy constraints are representing requirements given by standards and logical constraints are reflecting particular requirements on the designed concrete. In the considered case the following constraints have to be accounted for:

- Non-negativity constraint; $v_{s o l, k}>0$

- Volumetric constraint; $\Sigma v_{s o l, k}=1$

- Minimum cement content

- Maximum cement content

- Water/cement ration $(\mathrm{w} / \mathrm{c})$

- Water/powder ration (w/p)

- Ratio between binder 1 and binder $2\left(\mathrm{~B}_{1} / \mathrm{B}_{2}\right)$

Moreover, the total concrete volume $V_{\text {con }}$ of all concrete ingredients (including air and water) per $\mathrm{m}^{3}$ fresh concrete cannot be higher or lower than $1 \mathrm{~m}^{3}$ and follows from:

$$
\begin{aligned}
V_{c o n} & =V_{\text {sol }}^{t o t}+V_{w a t}+V_{a d m}+V_{a i r} \\
& =V_{a g g}+V_{c e m}+V_{f i l}+V_{w a t}+V_{a d m}+V_{a i r}=1 m^{3}
\end{aligned}
$$


Table 1. Mix proportioning of composed concrete mixes in $\mathrm{kg}$ per $\mathrm{m}^{3}$ concrete.

\begin{tabular}{|c|c|c|c|c|c|c|c|c|c|c|c|c|}
\hline Mix & $\begin{array}{l}\text { CEM I } \\
52.5 \mathrm{~N}\end{array}$ & $\begin{array}{l}\text { CEM III/B } \\
42.5 \mathrm{~N} \mathrm{LH} / \mathrm{HS}\end{array}$ & $\begin{array}{l}\text { Sand } \\
0-1\end{array}$ & $0-2$ & $0-4$ & $\begin{array}{l}\text { Gravel } \\
2-8\end{array}$ & $4-16$ & $8-16$ & Water & $\mathrm{w} / \mathrm{c}$ & $\mathrm{w} / \mathrm{p}$ & SP* \\
\hline Mix 1 & - & 310.0 & 482.8 & - & 475.4 & 584.8 & 366.0 & - & 139.5 & 0.45 & 0.41 & - \\
\hline Mix 2 & - & 310.0 & 482.8 & - & 475.4 & 584.8 & 366.0 & - & 139.5 & 0.45 & 0.41 & - \\
\hline Mix 3 & - & 310.0 & 88.6 & - & 594.1 & 818.7 & 448.8 & - & 124.0 & 0.40 & 0.39 & - \\
\hline Mix 4 & - & 310.0 & 227.8 & - & 604.7 & 605.0 & 512.7 & - & 124.0 & 0.38 & 0.37 & - \\
\hline Mix 5 & - & 310.0 & 92.0 & - & 599.5 & 826.2 & 452.9 & - & 116.2 & 0.38 & 0.37 & - \\
\hline Mix 6 & - & 310.0 & 92.0 & - & 599.5 & 826.2 & 452.9 & - & 116.2 & 0.38 & 0.37 & 0.63 \\
\hline Mix 7 & - & 310.0 & 92.0 & - & 599.5 & 826.2 & 452.9 & - & 116.2 & 0.38 & 0.37 & 0.94 \\
\hline Mix 8 & - & 310.0 & 92.0 & - & 599.5 & 826.2 & 452.9 & - & 116.2 & 0.38 & 0.37 & 0.93 \\
\hline Mix 9 & - & 310.0 & 400.2 & - & 522.7 & 599.2 & 448.6 & - & 116.3 & 0.38 & 0.35 & 0.63 \\
\hline Mix 10 & - & 310.0 & 400.2 & - & 522.7 & 599.2 & 448.6 & - & 116.3 & 0.38 & 0.35 & 0.94 \\
\hline Blend 1 & 130.0 & 245.0 & - & 698.0 & - & - & - & 356.0 & 131.3 & 0.35 & 0.34 & - \\
\hline Blend 2 & 112.7 & 212.3 & - & 602.0 & - & - & - & 396.9 & 113.7 & 0.35 & 0.34 & - \\
\hline Blend 3 & 112.7 & 212.3 & - & 602.0 & - & - & - & 396.9 & 113.7 & 0.35 & 0.34 & 1.63 \\
\hline Blend 4 & 112.7 & 212.3 & - & 602.0 & - & - & - & 396.9 & 113.7 & 0.35 & 0.34 & 0.98 \\
\hline
\end{tabular}

* SP: Superplasticizer

where $\quad V_{\text {agg }}=$ aggregate volume; $\quad V_{\text {cem }}=$ cement volume; $V_{\text {fil }}=$ filler volume; $V_{\text {wat }}=$ water volume; $V_{a d m}=$ admixture volume; and $V_{\text {air }}=$ air volume.

\section{CONCRETE EXPERIMENTS}

To demonstrate the suitability of geometric packing for EMC and the application of the modified A\&A equation, several concrete mixes have been designed and tested in the lab. The composition of the designed mixes is given in Table 1. For the mix design, three types of sand (0-1, 0-2 and 0-4), two types of gravel (4-16 and 8-16) and granite 2-8 are used. Slag cement or a blend of $65 \%$ slag cement and $35 \%$ Portland cement are used as binder. The air content per $\mathrm{m}^{3}$ fresh concrete is estimated a priori to be $0.04 \mathrm{~m}^{3}(=4.0 \%)$, this value needs to be verified later as it is depending on the packing fraction, the water content and the compaction efforts.

The designed concrete mixes are tested both in fresh and hardened state. The consistence of the concrete mix in fresh state is assessed by the degree of compactibility $c$ (compaction index) according to DIN-EN 12350-4 (1999). The tested EMC mixtures resulted in values between 1.40 and 1.65 for the degree of compactibility and can therefore be classified as zero slump concrete.

Based on the mix proportioning, the packing fraction $P F$ of the fresh concrete mixes in loose as well as dense state can be computed as follows:

$$
P F=\frac{V_{s o l}}{V_{v e s}}=\frac{\sum_{k=1}^{m-2} \frac{1}{\rho_{s o l, k}^{s p e}} \frac{M_{s o l, k}}{M_{c o n}} M_{v e s}}{V_{v e s}}
$$

where $V_{\text {sol }}=$ solid volume; $M_{\text {con }}=$ concrete mass; $M_{s o l, k}=$ mass of solid $k$; and $M_{v e s}=$ mess of the measuring vessel.

The computed packing fraction uses the density of the fresh concrete densely and loosely packed in a round vessel having a fixed volume of 8 liters and a diameter of $205 \mathrm{~mm}$.

Furthermore, the degree of saturation of the void fraction can be computed and reflects the ratio of the total volume of water to the total volume of voids using the values of the packing fraction as well as the water content of the mix as follows:

$S=\frac{V_{w}}{V_{\text {void }}}$

where $V_{w}=$ water volume; and $V_{\text {void }}=$ void fraction.

The designed mixes have been poured in standard cubes, cured sealed during the first day, demolded, and subsequently cured for 27 days submersed in a water basin at $20 \pm 2{ }^{\circ} \mathrm{C}$. After 28 days, the cubes are tested for compressive strength. The compressive strength $f_{c}$ of each cube is determined according to the standard DIN-EN 12390-4 (2002). The mean values of the compressive strength of each tested series, based on three cubes per series, are depicted in Figure 3.

As the amount of cement per $\mathrm{m}^{3}$ fresh concrete as well as the applied w/c ratio is varying marginally, it can be assumed that the increase in the compressive strength for mixes having higher packing fractions is caused by an improved granular structure. The positive relation between higher values of the packing fraction due to an improved packing of the solids and improved mechanical properties is one of the basic features of the new mix design concept.

But not only the compressive strength of a mixture can be improved by an optimized and dense packing 


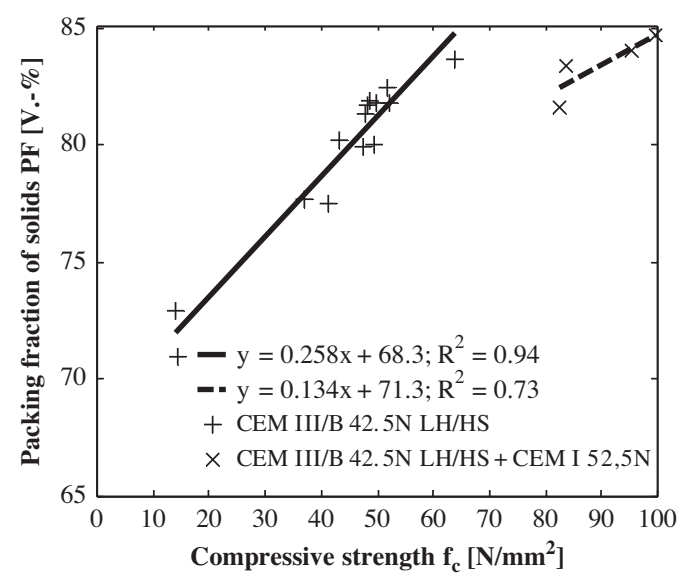

Figure 3. Measured packing fraction versus compressive strength.

Table 2. Compressive strength (28 days), packing fraction and computed cement efficiency for tested concrete mixtures.

\begin{tabular}{lclll}
\hline & $\begin{array}{l}\text { Compr. } \\
\text { Strength } f_{c}\end{array}$ & $\begin{array}{l}\text { Packing } \\
\text { Fraction } \\
\text { Specimen } \\
{\left[\mathrm{N} / \mathrm{mm}^{2}\right]}\end{array}$ & $\begin{array}{l}\text { Cement } \\
\text { Efficiency } x_{c}\end{array}$ & $\begin{array}{l}\text { Saturation } \\
{\left[\mathrm{Nm}^{3} / \mathrm{kgmm}^{2}\right]}\end{array}$ \\
{$\left[\begin{array}{l}\left.\mathrm{K}^{2}\right] \\
\text { Mix 1 }\end{array}\right.$} & 41.1 & 77.5 & 0.133 & 62.0 \\
Mix 2 & 36.9 & 77.7 & 0.119 & 62.6 \\
Mix 3 & 48.8 & 81.9 & 0.157 & 68.5 \\
Mix 4 & 52.3 & 81.8 & 0.169 & 68.1 \\
Mix 5 & 48.2 & 81.7 & 0.156 & 63.5 \\
Mix 6 & 47.3 & 79.9 & 0.153 & 57.8 \\
Mix 7 & 49.9 & 81.8 & 0.161 & 63.8 \\
Mix 8 & 63.7 & 83.6 & 0.205 & 70.9 \\
Mix 9 & 43.0 & 80.2 & 0.139 & 58.7 \\
Mix 10 & 48.0 & 81.3 & 0.155 & 62.2 \\
Blend 1 & 82.6 & 81.6 & 0.216 & 71.4 \\
Blend 2 & 83.5 & 83.5 & 0.235 & 68.9 \\
Blend 3 & 95.3 & 84.0 & 0.279 & 71.1 \\
Blend 4 & 100.2 & 84.7 & 0.308 & 74.3 \\
\hline
\end{tabular}

of all granular ingredients, but also the cement can be used more efficiently.

This is indicated by the compressive strength cement efficiency $x_{c}$ or the flexural strength cement efficiency $x_{f}$ of the concrete mixture and described by:

$x_{c}=\frac{f_{c}}{M_{c e m}}$ and $x_{f}=\frac{f_{f}}{M_{c e m}}$

where $f_{c}=$ compressive strength; $f_{f}=$ flexural strength; and $M_{c e m}=$ mass of cement per $\mathrm{m}^{3}$ concrete. The computed values for the compressive strength cement efficiency are given in Table 2 combined with the obtained packing fractions and compressive strength values. Based on the values given in Table 2, the cement efficiency could be increased for mixtures using only slag cement, from 0.13 up to $0.21 \mathrm{Nm}^{3} / \mathrm{kgmm}^{2}$. For mixtures using a blend of $65 \%$ slag cement and $35 \%$ Portland cement the cement efficiency could even be improved from 0.22 to $0.31 \mathrm{Nm}^{3} / \mathrm{kgmm}^{2}$ by means of an optimized particle packing.

Considering both the high compressive strength values of mixes having high packing fractions and improvements regarding a more efficient use of cement, reducing the cement content of the designed concrete mixtures is one of the major interests for the further research.

Following the idea of eco EMC, the application of stone waste materials should be preferred as they are produced in large quantities.

\section{STONE WASTE MATERIALS}

During the production of washed rock aggregates, high amounts of fine stone waste powders with particle size $<125 \mu \mathrm{m}$ are generated in slurry form throughout the washing process. The material characterization, particularly with respect to particle size distribution at present, showed that this type of waste material can be used as cement replacement in order to turn the production process of the broken rock aggregates as well as the concrete production to a more sustainable and environmental friendly process.

Depending on the origin and the generation of the stone waste materials, different approaches are possible for the application of stone waste materials in concrete. In this part of the research, the direct use of the untreated and unwashed intermediate product is favored. In this case, the stone waste material will not be generated as the original product allows a direct use of the material in special types of concrete (e.g. EMC or SCC). This method will result in higher financial and environment-friendly aspects as an intermediate step in the production of broken rock aggregates is eliminated. Therefore, the direct use of this untreated product, its sand fraction here named Premix $0-4$, was focused.

Four different EMC mixes having varying cement contents are designed by means of the ideas of the new mix design concept and tested on mortar base as mortar tests permit a quick and handy preliminary evaluation of the designed mixtures. Table 3 shows the composition of the tested concrete mixes serving as starting point for the mortar tests.

The designed mixes are using premixed sand (Premix 0-4), containing both fine aggregate and inert stone powder, in combination with varying cement contents. The distribution modulus $q$ is chosen to be 0.35 for all mixes. Considering a distribution modulus of $q=0.35$ and a $\mathrm{w} / \mathrm{p}$ ratio of 0.35 , the necessary 
Table 3. Mix proportioning of composed concrete mixes containing stone waste material.

\begin{tabular}{|c|c|c|c|c|c|c|c|c|}
\hline Mix & $\begin{array}{l}\text { CEM I } \\
52.5 \mathrm{~N}\end{array}$ & $\begin{array}{l}\text { CEM III/B } \\
42.5 \mathrm{~N} \mathrm{LH} / \mathrm{HS}\end{array}$ & Premix $0-4$ & Granite $2-8$ & Gravel 8-16 & Water & $\mathrm{w} / \mathrm{c}$ & $\mathrm{w} / \mathrm{p}$ \\
\hline Premix C275 & 95.3 & 179.7 & 999.6 & 377.4 & 583.3 & 118.3 & 0.43 & 0.33 \\
\hline Premix C250 & 75.0 & 175.0 & 1034.5 & 346.8 & 591.8 & 121.6 & 0.49 & 0.33 \\
\hline Premix C200 & 60.0 & 140.0 & 1140.3 & 283.6 & 626.6 & 109.1 & 0.55 & 0.33 \\
\hline Premix C175 & 52.5 & 122.5 & 1182.9 & 252.0 & 638.8 & 108.7 & 0.62 & 0.35 \\
\hline
\end{tabular}

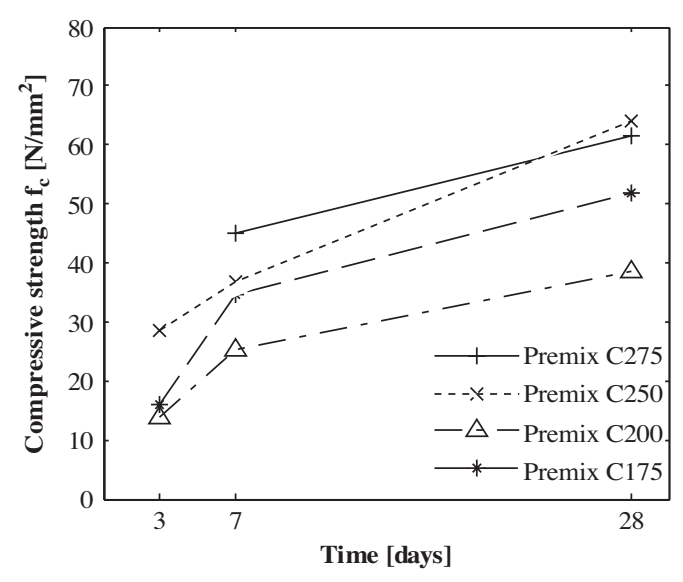

Figure 4. Mean compressive strength of tested mortar samples.

cement content amounts to $235 \mathrm{~kg}_{\text {per }} \mathrm{m}^{3}$ fresh concrete to follow the given target line with the lowest deviation.

For the mortar experiments, the cement content is reduced starting from $275 \mathrm{~kg}$ down to $175 \mathrm{~kg}$ per $\mathrm{m}^{3}$ fresh concrete and is compensated by higher amounts of Premix 0-4 and gravel as well. For designing the concrete mixtures, a blend of $65 \%$ slag cement (CEM III/B $42.5 \mathrm{~N} \mathrm{LH} / \mathrm{HS}$ and $35 \%$ Portland cement (CEM I $52.5 \mathrm{~N}$ ) was used.

Due to the high content of fines and low cement contents in the mixtures, the amount of water is maintained as low as possible in order to achieve $\mathrm{w} / \mathrm{c}$ ratios around 0.50 . Therefore, the use of plasticizers is necessary to match the industrial compaction efforts with available compaction efforts under laboratory conditions.

The mortar samples are tested regarding their compressive strength as well as flexural strength. For testing the compressive strength, cubes with dimensions of $50 \times 50 \times 50 \mathrm{~mm}$ have been produced using constant compaction efforts, cured sealed during the first day, demolded, and subsequently cured submersed in a water basin at $20 \pm 2^{\circ} \mathrm{C}$. The produced cubes have been tested after 3, 7 and 28 days. The mean values of the compressive strength tests are depicted in Figure 4.
It seems that the compressive strength after 28 days of the mortar samples having a cement content of $275 \mathrm{~kg}$ and $250 \mathrm{~kg}$ per $\mathrm{m}^{3}$ fresh concrete is not influenced by the cement content of the designed mixtures. Here, the mix having a cement content of $250 \mathrm{~kg}$ cement per $\mathrm{m}^{3}$ fresh concrete achieves the same compressive strength after 28 days as the mix having $275 \mathrm{~kg}$. The optimum cement content for following the given target line with the lowest deviation amounts to $235 \mathrm{~kg}$. This amount of cement results from the granulometric properties (PSD) of the used materials in combination with a distribution modulus of $q=0.35$ (Equation 2).

It appears that a reduction in the cement content is not influencing the compressive strength when the original cement content is already higher than actually needed. In this case, the additional cement only acts as a kind of filling material. The reduction in the cement content shows higher effect on the compressive strength if the cement content is already below the necessary amount needed for optimum packing and a further reduction in the cement content is then influencing the granular structure in a negative way.

Considering the data of the mix proportioning given in Table 3, the $\mathrm{w} / \mathrm{p}$ ratio and the workability is constant for mixes having a cement content of 275, 250 and $200 \mathrm{~kg}$ per $\mathrm{m}^{3}$ fresh concrete.

But the w/p ratio was increased from 0.33 to 0.35 for the mix having $175 \mathrm{~kg}$ per $\mathrm{m}^{3}$ fresh concrete. This slightly increase in the water content improved the workability properties of the mixtures and the granular structure of the hardened concrete. Therefore, the mix containing $175 \mathrm{~kg}$ cement per $\mathrm{m}^{3}$ fresh concrete achieved higher compressive strength values than the mix using $200 \mathrm{~kg}$ cement per $\mathrm{m}^{3}$ fresh concrete. The highest cement efficiency for the compressive strength test, considering a constant $\mathrm{w} / \mathrm{p}$ ratio, has been achieved for the EMC mix using $250 \mathrm{~kg}$ cement per $\mathrm{m}^{3}$ fresh concrete. The present results regarding the compressive strength show therefore that cement can be used more efficient when the mix design results in an optimized particle packing.

Significant variations on the flexural strength in dependence on the varying cement contents are only recognizable for the strength development up to seven days. To show the effect of cement reduction clearly on 


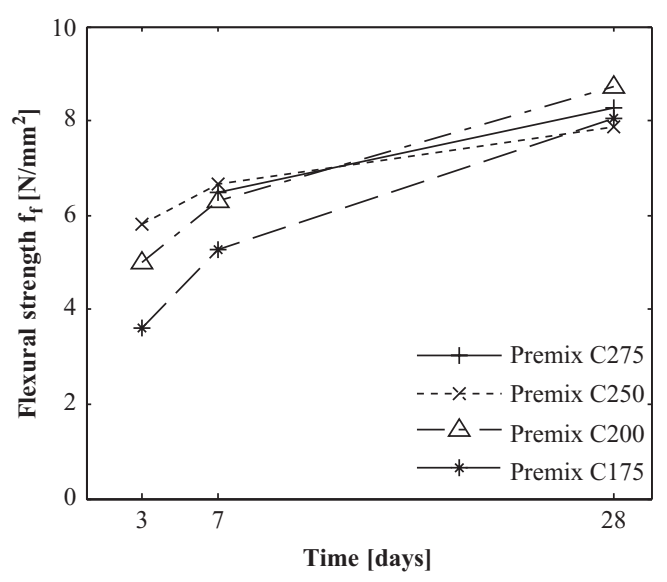

Figure 5. Mean flexural strength of tested mortar prisms.

Table 4. Test results and computed cement efficiency for tested mortar mixtures (28 days).

\begin{tabular}{lll}
\hline & $\begin{array}{l}\text { Compr. Strength } \\
\text { Cement Efficiency } \\
x_{c}\left[\mathrm{Nm}^{3} / \mathrm{kgmm}^{2}\right]\end{array}$ & $\begin{array}{l}\text { Flexural Strength } \\
\text { Cement Efficiency } \\
x_{f}\left[\mathrm{Nm}^{3} / \mathrm{kgmm}^{2}\right]\end{array}$ \\
\hline Premix C275 & 0.225 & $3.02 \mathrm{E}-02$ \\
Premix C250 & 0.255 & $3.16 \mathrm{E}-02$ \\
Premix C200 & 0.192 & $4.35 \mathrm{E}-02$ \\
Premix C175 & 0.297 & $4.63 \mathrm{E}-02$ \\
\hline
\end{tabular}

the results of the flexural strength tests after 28 days is hardly possible as the standard deviation for each particular series is higher than the difference of the mean values among each other.

All tested series using Premix 0-4 showed high flexural strength values in the range between 7.9 and $8.1 \mathrm{~N} / \mathrm{mm}^{2}$. These high values of the flexural strength are caused by the angular shape of the broken material (Premix 0-4).

Due to the marginal difference between the values of the flexural strength, the cement efficiency regarding flexural strength is increasing with decreasing cement contents. This points out clearly that the cement can also be used in a more efficient way when the flexural strength is considered.

\section{DISCUSSION}

The tests on EMC learned that a general relation between the distribution modulus of the modified A\&A equation and the packing fraction can be derived. Based on the data obtained from the concrete experiments, the relation between distribution modulus and packing fraction is shown in Figure 6. It becomes

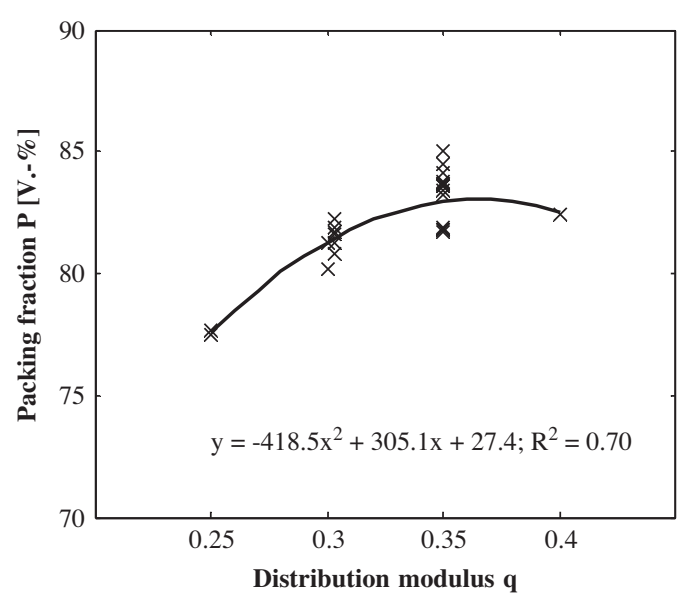

Figure 6. Influence of various distribution moduli on the packing fraction.

clear from Figure 6 that highest packing fractions have been achieved for a distribution modulus of $q=0.35$. The same fact applies for the compressive strength of the hardened concrete. Here, mixes with a distribution modulus of $\mathrm{q}=0.35$ and high packing fractions achieved higher compressive strength values than the mixes with lower packing fractions, caused by their lower distribution moduli.

Besides the use of suitable distribution moduli for composing concrete aggregates, some further properties of the fresh concrete mix are also important for workable concrete mixes and partly influenced by the chosen distribution modulus. Based on the analysis of the obtained test results, the following values are advisable for the characterization of workable EMC mixes:

- Distribution modulus (q): 0.35-0.40

- Paste content $(<125 \mu \mathrm{m}): 0.225-0.250 \mathrm{~m}^{3}$ per $\mathrm{m}^{3}$ fresh concrete

- w/p ratio ( $<125 \mu \mathrm{m}): 0.30-0.35$

Traditional EMC mixes are characterized by low contents of fine inert or reactive filler materials. Therefore, the difference between the $\mathrm{w} / \mathrm{c}$ ratio and the $\mathrm{w} / \mathrm{p}$ ratio is small or nonexistent for these mixes when using a classical design approach. Decreasing cement contents and increasing amounts of filler materials, however, augments the difference between the w/c and the $\mathrm{w} / \mathrm{p}$ ratio. Considering the desired workability of the concrete as a function of the $\mathrm{w} / \mathrm{p}$ ratio, it is more appropriate for the mix design to take the $\mathrm{w} / \mathrm{p}$ ratio into account than the $\mathrm{w} / \mathrm{c}$ ratio.

This fact is also reflected by the strength development of the tested mortar samples depicted in Figure 4. The mix having a cement content of $175 \mathrm{~kg} \mathrm{per} \mathrm{m}^{3}$ fresh concrete and a w/c ratio of $0.62(\mathrm{w} / \mathrm{p}=0.35)$ 
achieved higher compressive strength values after 28 days than the mix containing $200 \mathrm{~kg}$ cement per $\mathrm{m}^{3}$ fresh concrete and the corresponding lower $\mathrm{w} / \mathrm{c}$ ratio of $0.55(\mathrm{w} / \mathrm{p}=0.33)$. The higher compressive strength of the mix containing less cement is caused by a better workability due to a slightly higher $\mathrm{w} / \mathrm{p}$ ratio. The difference in the $\mathrm{w} / \mathrm{p}$ ratio improved the packing of the mix using constant compaction efforts. Considering the $\mathrm{w} / \mathrm{c}$ ratio of the two mixes, this is in contrast to the observations made by Locher (1976) on cement stone regarding cement hydration and strength development of the hardening cement stone.

According to Locher (1976), an increase in the w/c ratio is resulting in higher values of the capillary porosity. Caused by the remaining water content, capillary pores are formed which will be filled with hydration products in a progressed hydration state. As a result of increasing $\mathrm{w} / \mathrm{c}$ ratios, also the capillary porosity of the cement stone is increasing, which makes the cement stone weak. Therefore, an increase in the $\mathrm{w} / \mathrm{c}$ ratio will result in a decrease in the compressive strength. This is not affirmed by the conducted experiments as a possible reduction in the compressive strength of the cement stone is compensated by a positive influence on the compressive strength of an optimized and denser granular structure. So, it appears that the absolute water content in a mix is more relevant than the $\mathrm{w} / \mathrm{c}$ ratio.

Furthermore, it is of great interest for EMC mixes to consider also the degree of saturation of the fresh concrete mix as the formation of the capillary forces is connected to the air/water saturation in the void fraction. This value was also computed for the designed mixtures and is given in Table 2 . The designed mixes are having values between $58 \%$ and $75 \%$ and can therefore be classified as 'moist' according to soil mechanical definitions.

Nevertheless, the use of low $\mathrm{w} / \mathrm{c}$ ratios is still important for the durability properties of the concrete as the capillary pores are influencing the impermeability as well as the durability of the hardened concrete. But the application of high contents of fine materials (e.g. stone waste materials) seems to be hindering for this purpose as the water demand and therewith the w/c ratio is increasing with increasing amounts of fine materials. Here, the application of plasticizers showed a positive effect. Due to the use of plasticizers, the workability of EMC mixes has been improved for mixes containing high amounts of fine materials and low w/c ratios. Packing fractions between 84 and $85 \%$ have been achieved in the lab by using paste content of $0.246 \mathrm{~m}^{3}$ per $\mathrm{m}^{3}$ concrete with a w/p ratio of 0.33 . These mixes have been resulted in high 28 days compressive strength values between 95.7 and $100.3 \mathrm{~N} / \mathrm{mm}^{2}$.

Using the Premix 0-4, the cement content can be reduced without changes in the entire PSD of the designed mix since a suitable filler material is provided by this premixed and unwashed aggregate. This allows a more efficient use of the binding material by means of an optimized granular structure and suitable filler materials.

\section{CONCLUSIONS}

This paper demonstrates that the packing of all solids is of fundamental importance for the aimed optimization of the properties of earth-moist concrete, both in fresh and hardened states. An optimization in the packing improves the properties of the fresh concrete (water demand, compactibility, green strength) and therefore the properties of the hardened concrete as well.

The new mix design concept has proved its potential for a performance based composition of concrete mixes considering the granular properties of the granular ingredients such as particle size, particle shape and surface texture. Thereby, the improvement of the concrete properties is based upon an aimed optimization of the entire particle size distribution of all solids in the mix. For the optimization of the composed PSD, the geometric packing of continuously graded particles following the modified equation of Andreasen and Andersen, according to Funk and Dinger (1994), is employed.

The results show that hardened concrete achieves higher compressive strength values if an improved granular structure can be achieved. This includes both an increase in the grain-to-grain points of contact and a better packing of the aggregates used.

Considering both the enhancement in the compressive strength as well as the improved cement efficiency, the study reveals how the optimum packing of all concrete ingredients is influencing the mechanical properties positively. Particular attention should not only be paid to high compressive strength values, but also to the fact that a part of the cement seems to be unused if the granular structure of the hardened concrete is very porous and weak due to poor packing of the solids. This causes the addition of cement in order to increase the compressive strength of the hardened concrete. Whereas the added cement is used as a filler material instead of a binding material which contributes primarily to the strength development of the hardened concrete.

In view of the market prices for cement as well as the energy consumption involved with cement production, this is hardly acceptable for the mass production of concrete products. For the production of cost efficient and environmental friendly concrete products, the cement content should be reduced to a minimum amount necessary for fulfilling the demands on the mechanical and durability properties. This can be achieved by means of an optimum packing and the 
application of fine stone waste materials as substituent for primary raw materials.

Furthermore, the use of superplasticizers showed good results for EMC mixes containing high powder contents. By means of plasticizers, the amount of fine inert particles could be increased without increasing the water content of the mix or a loss in the workability of the concrete mix.

Within the conducted research the new mix design concept showed its suitability for the optimization of the PSD of the composed concrete mix, both for the optimization of already used mixtures and the composition of new mixes containing fine inert filling materials in form of stone waste powders. Moreover, this approach allows for a more performance based mix design of EMC concrete mixes.

\section{ACKNOWLEDGEMENTS}

The authors wish to express their sincere thanks to the European Commission (I-Stone Project, Proposal No. 515762-2) and the following sponsors of the research group: Bouwdienst Rijkswaterstaat, Rokramix, Betoncentrale Twenthe, Betonmortelcentrale Flevoland, Graniet-Import Benelux, Kijlstra Beton, Struyk Verwo Groep, Hülskens, Insulinde, Dusseldorp Groep, Eerland Recycling, Enci, Provincie Overijssel, Rijkswaterstaat Directie Zeeland, A\&G Maasvlakte (chronological order of joining).

\section{REFERENCES}

Andreasen, A.H.M. \& Andersen, J. 1930. Ueber die Beziehungen zwischen Kornabstufungen und Zwischenraum in Produkten aus losen Körnern (mit einigen Experimenten). Kolloid-Zeitschrift 50: 217-228.
Brouwers, H.J.H. \& Radix, H.J. 2005. Self-Compacting Concrete: Theoretical and experimental study. Cement and Concrete Research 35: 2116-2136.

DIN Deutsches Institut für Normung e. V. 1999, DIN-EN 12350-4: Testing fresh concrete - Part 4: Degree of compactibility; German version EN 12350-4:1999. Berlin: Beuth Verlag GmbH.

DIN Deutsches Institut für Normung e. V. 2002, DIN-EN 12390-4: Testing hardened concrete-Part 3: Compressive strength of test specimens; German version EN 12390 4:2000. Berlin: Beuth Verlag GmbH.

Dutch Normalization-Institute. 1995. NEN 5950: Voorschriften Beton Technologie - Eisen, vervaardiging en keuring. Delft: Nederlands Normalisatie Instituut.

Fuller, W.B. \& Thompson S.E. 1907. The laws of proportioning concrete. Transactions of the American Society of Civil Engineers 33: 222-298.

Funk, J.E. \& Dinger, D.R. 1994. Predictive Process Control of Crowded Particulate Suspensions: Applied to Ceramic Manufacturing. Boston: Kluwer Academic Press.

Hummel, A. 1959. Das Beton-ABC-Ein Lehrbuch der Technologie des Schwerbetons und des Leichtbetons. Berlin: Verlag von Wilhelm Ernst \& Sohn.

Hunger, M. \& Brouwers, H.J.H. 2006. Development of Self-Compacting Eco-Concrete. In H.B. Fischer (ed.), Proc. 16th Ibausil, International Conference on Building Materials, Weimar, 20-23 September 2006, Weimar: F.A. Finger-Institut für Baustoffkunde.

Locher, F.W. 1976. Die Festigkeit des Zements. Beton 26(8): 283-286.

Schmidt, M., Bornemann, R. \& Bilgeri, P. 2005. Entwicklung optimierter hüttensandhaltiger Zemente für den Einsatz in der Betonwarenindustrie. Betonwerk International 2005(3): 62-72. 